\title{
Spray-drying microencapsulation of synergistic antioxidant mushroom extracts and their use as functional food ingredients
}

Running title: Mushroom functional food ingredients

Andreia Ribeiro ${ }^{\mathrm{a}, \mathrm{b}}$, Gabriela Ruphuy ${ }^{\mathrm{b}, \mathrm{c}}$, José Carlos Lopes $^{\mathrm{c}}$, Madalena Maria Dias ${ }^{\mathrm{c}}$, Lillian Barros $^{\mathrm{a}}$, Filomena Barreiro ${ }^{\mathrm{b}, *}$, Isabel C.F.R. Ferreira ${ }^{\mathrm{a}, ~ *}$

${ }^{a}$ Mountain Research Center (CIMO), ESA, Polytechnic Institute of Bragança, Campus Santa Apolónia Ap. 1172, 5301-855 Bragança, Portugal.

${ }^{b}$ Laboratory of Separation and Reaction Engineering (LSRE), Associate Laboratory LSRE/LCM, Polytechnic Institute of Bragança, Campus Santa Apolónia Ap. 1134, 5301-857 Bragança, Portugal.

${ }^{c}$ Laboratory of Separation and Reaction Engineering (LSRE) - Associate Laboratory LSRE/LCM, Faculty of Engineering, University of Porto, Porto, Portugal

*Authors to whom correspondence should be addressed (I.C.F.R. Ferreira- e-mail: iferreira@ipb.pt telephone +351-273-303219; fax +351-273-325405; M.F. Barreiro- email: barreiro@ipb.pt; telephone +351-273-303089; fax +351-273-325405). 


\begin{abstract}
In this work, hydroalcoholic extracts of two mushrooms species, Suillus luteus (L.: Fries) ( $\mathrm{Sl}$ ) and Cropinopsis atramentaria (Bull.) (Ca), were studied for their synergistic antioxidant effect and their viability as functional food ingredients tested by incorporation into a food matrix (cottage cheese). In a first step, the individual extracts and a combination of both showing synergistic effects (Sl:Ca, 1:1) were microencapsulated by spray-drying using maltodextrin as the encapsulating material. The incorporation of free extracts resulted in products with higher initial antioxidant activity (t0) but declining after 7 days (t7), which was associated with their degradation. However, the cottage cheese enriched with the microencapsulated extracts, that have revealed a lower activity at initial time, showed an increase at $\mathrm{t} 7$. This improvement can be explained by an effective protection provided by the microspheres together with a sustained release. Analyses performed on the studied cottage cheese samples showed the maintenance of the nutritional properties and no colour modifications were noticed.
\end{abstract}

Keywords: Mushroom extracts; antioxidant activity; synergistic effects; microencapsulation; cottage cheese 


\section{Introduction}

Mushrooms are widely appreciated all over the world for their nutritional properties (Kalač, 2009). They have a low fat content but are rich in water, minerals, proteins, fibres and carbohydrates (Heleno, Barros, Martins, Queiroz, Santos-Buelga \& Ferreira, 2012; Kalač, 2009; Reis et al., 2011; Reis, Barros, Martins \& Ferreira, 2012;). Besides their nutritional value, it has been demonstrated that mushrooms have health promoting benefits (Palacios et al., 2011). They are effective as anti-inflammatory (Ma, Chen, Dong \& Lu, 2013), antitumor (Heleno, Ferreira, Calhelha, Esteves, Martins \& Queiroz, 2014), antibacterial (Alves, Ferreira, Martins \& Pintado, 2012) and antioxidant agents (Reis et al., 2011), extending their potential use to functional foods and applications in the biomedical field.

During natural cellular metabolism, reactive oxygen (ROS), nitrogen (RNS) and sulphur (RSS) species are produced (Carocho \& Ferreira, 2013), being ROS the most abundant ones (Ferreira, Barros \& Abreu, 2009). When high concentrations of these species are present, an oxidative stress is generated. If in excess, ROS may oxidize and damage cellular lipids, proteins and DNA, leading to their modification and inhibition of normal functions (Ferreira et al., 2009). Given this scenario, the organism develops defence mechanisms such as endogenous defences, which can be of enzymatic type, leading to the production of superoxide dismutase (SOD), catalase (CAT), glutathione peroxidase (GSH-Px) and glutathione reductase; or non-enzymatic, resulting in species such as glutathione (GSH), $\alpha$-tocopherol (vitamin E), ascorbic acid (vitamin C) and lipoic acid (Carocho \& Ferreira, 2013; Ferreira et al., 2009). Both mechanisms are able to provide cells protection against excessive levels of free radicals (Carocho \& Ferreira, 2013). 
The exogenous antioxidant defence promoters can be ingested as part of the daily diet to help fight against high ROS contents. Therefore, mushrooms can play an important role since they contain diverse phenolic compounds, known to be excellent antioxidants due to their capacity for capturing free radicals by electron transferring, and to the excellent redox properties of the phenolic hydroxyls groups (Ferreira et al., 2009).

Apart from their instability at high temperatures, and in the presence of oxygen and light, some mushroom extracts are characterized by a strong odour and flavour. One way to ensure their viability as functional food ingredients is to proceed with their microencapsulation, providing protection against oxidation and masking odour and flavour (Ersus \& Yurdagel, 2007; Fang \& Bhandari, 2010). Despite the numerous available microencapsulation possibilities, spray-drying is still one of the most widely used processes to encapsulate food ingredients (Fang \& Bhandari, 2010). Among the main advantages of this technique are its easy industrialization and possibility of continuous production. Nevertheless, prolonged contact with high temperatures can compromise the bioactive properties of the mushroom extracts, and should be avoided. Among several possibilities, maltodextrin (MD), a hydrolysed starch, offers advantages as microencapsulation material (Gharsallaoui, Roudaut, Chambin, Voilley \& Saurel, 2007). It is a low cost material with neutral aroma and flavour, high water solubility, low viscosity at high solids content, being able to provide an effective protection against oxidation (Ersus \& Yurdagel, 2007; Saénz, Tapia, Chávez \& Robert, 2009).

Microencapsulation can be applied to protect bioactive natural extracts and some examples calling up this thematic can be found in literature (Dias, Ferreira \& Barreiro, 2015). Nevertheless, these studies are mainly related with the microencapsulation process development and do not proceed with the implementation of a final application 
(functional food) (Ersus \& Yurdagel, 2007; Kha, Nguyen \& Roach, 2010; Silva, Stringheta, Teófilo \& Oliveira, 2013; Saénz et al., 2009; Wu, Zou, Mao, Huang \& Liu, 2014). In fact, and according to the performed research, the examples dealing with the full process development are scarcer. In this context, Çam, Içyer \& Erdoğna, (2014) tested the incorporation of microencapsulated Punica granatum L., an extract from pomegranate, in ice creams, and Martins et al., (2014) studied the incorporation of Rubus ulmifolius Schoot (Rosaceae), a species of wild blackberry, microencapsulated in alginate microparticles, in a dairy product, yogurt. The obtained results, rather preliminary, are motivating corroborating the interest of developing foods enriched with natural extracts that are often referred as health promoters (Ramalingum \& Mahomoodally, 2014).

In this work, extracts of two mushroom species, Suillus luteus (L.: Fries) and Cropinopsis atramentaria (Bull.) were investigated for their synergistic antioxidant effects and a promising combination of both (in similar proportions) was chosen to be microencapsulated by spray-drying using maltodextrin as the encapsulating material. The obtained powders were characterized by Scanning Electron Microscopy (SEM) (to inspect morphology and particle size) and for their antioxidant activity (free radicals scavenging activity and reducing power). Encapsulation yield and efficiency were also estimated. As a final step of this work the produced microspheres were incorporated in cottage cheese samples and its antioxidant activity, nutritional value and colour were determined and compared with the counterparts using extracts in its free form and a control (sample with no added extracts).

\section{Materials and methods}




\subsection{Standards and reagents}

For antioxidant tests, 2,2-dipheny-1-picrylhydrazyl (DPPH) was obtained from Alfa Aesar (Ward Hill, MA, USA). For chromatographic analysis, HPLC-grade acetonitrile was from Fisher Scientific (Lisbon, Portugal). The standards, such as fatty acids methyl ester (FAME) reference standard mixture 37 (standard 47885-U), $\beta$-carotene (98\%) and trolox (6-hydroxy-2,5,7,8-tetramethylchroman-2-carboxylic acid) were purchased from Sigma (St. Louis, MO, USA), as also formic acid. Maltodextrin (MD) was provided by Cargill (Wayzata, MN, USA) with dextrose equivalent of 18. All other chemicals and solvents were of analytical grade and purchased from common sources. Water was treated in a Milli-Q water purification system (TGI Pure Water Systems, Greenville, SC, USA).

\subsection{Preparation of mushroom extracts and evaluation of synergistic effects}

\subsubsection{Extracts preparation}

Mushroom samples, Suillus luteus (Sl) and Cropinopsis atramentaria (Ca), were harvested in Bragança region located at the North-eastern of Portugal, according to a previous report of the authors (Heleno et al., 2012; Reis et al., 2011). The chemical characterization of both species can be found in the cited references.

Samples of individual species and combinations in three different proportions (Sl:Ca 1:2, $1: 1$ and $2: 1, \mathrm{w} / \mathrm{w})$ were extracted. To prepare the extracts, the lyophilized mushroom samples $(1.5 \mathrm{~g})$ were extracted with methanol/water $(80: 20, \mathrm{v} / \mathrm{v}, 30 \mathrm{~mL})$ at room temperature during $1 \mathrm{~h}$ under stirring. The extract was filtered through a Whatman paper filter $\mathrm{N}^{\circ} 4$ and the remaining residue subjected to an additional extraction. The 
combined extracts were evaporated under reduced pressure in a rotatory evaporator (Büchi R-210, Flawil, Switzerland) until complete removal of methanol, lyophilized (FreeZone 4.5, Labconco, Kansas City, MO, USA) and stored in a desiccator protected from light until use.

\subsubsection{Evaluation of antioxidant activity}

The antioxidant activity of the obtained extracts was evaluated by using the DPPH radical scavenging activity, reducing power and inhibition of $\beta$-carotene bleaching assays. For the assays, the extracts were re-dissolved in methanol/water $(80: 20, \mathrm{v} / \mathrm{v})$ at $20 \mathrm{mg} / \mathrm{mL}$, and stored at $4{ }^{\circ} \mathrm{C}$. These stock solutions were successively diluted to determine $\mathrm{EC}_{50}$ values (sample concentration providing a value of $50 \%$ in the DPPH and $\beta$-carotene bleaching assays or an absorbance value of 0.5 in the reducing power assay).

DPPH radical scavenging activity (Heleno et al., 2012) was evaluated using an ELX800 microplate Reader (Bio-Tek Instruments, Inc., Winooski, VT, USA), and calculated as a percentage of DPPH discoloration using the formula: $\left[\left(A_{D P P H}-A_{S}\right) / A_{D P P H}\right] \times 100$, where $A_{S}$ is the absorbance of the solution containing the sample at $515 \mathrm{~nm}$, and $A_{D P P H}$ is the absorbance of the DPPH solution. Reducing power (Heleno et al., 2012) was evaluated by the capacity to convert $\mathrm{Fe}^{3+}$ into $\mathrm{Fe}^{2+}$, measuring the absorbance at $690 \mathrm{~nm}$ in the microplate reader mentioned above. Inhibition of $\beta$-carotene bleaching (Heleno et al., 2012) was evaluated by the $\beta$-carotene/linoleate assay; the neutralization of linoleate free radicals avoids $\beta$-carotene bleaching, which is measured by the formula: ( $\beta$ carotene absorbance after $2 \mathrm{~h}$ of assay/initial absorbance) $\times 100$. Trolox was used as positive control. 


\subsubsection{Classification of additive, synergistic or antagonistic effects}

Theoretical values of the antioxidant activity of the assayed mixture extracts were calculated as the weighted mean of the experimentally determined $\mathrm{EC}_{50}$ values of the individual extracts and considering additive contributions, e.g., for a mixture comprising $33 \%(\mathrm{w} / \mathrm{w})$ of $S$. luteus and $67 \%(\mathrm{w} / \mathrm{w})$ of $C$. atramentaria, $\mathrm{EC}_{50}=\mathrm{EC}_{50}$ S. luteus $\times 0.33$ $+\mathrm{EC}_{50}$ C. atramentaria $\times 0.67$.

The classification as additive (AE), synergistic (SE) or antagonistic (negative synergistic (NS)) effects was performed as follow: $\mathrm{AE}$ : $\mathrm{EC}_{50}$ theoretical and experimental values revealed differences lower than 5\%; SE: $\mathrm{EC}_{50}$ experimental values were at least 5\% lower than theoretical values; $\mathrm{AN}$ : $\mathrm{EC}_{50}$ experimental values were at least $5 \%$ higher than theoretical values. The limit of 5\% was chosen taking into account the coefficients of variation obtained in the replications of each antioxidant activity assay. It should be noted that lower $\mathrm{EC}_{50}$ values means higher antioxidant activity.

\subsection{Microencapsulation of mushroom extracts and characterization}

\subsubsection{Microencapsulation}

Microencapsulation was performed by spray-drying using the lyophilized extracts and maltodextrin (MD) as the encapsulating material. The used spray-drying conditions were adapted from the best ones achieved in the work of $\mathrm{Wu}$ and co-workers (Wu et al., 2014) that comprise the preparation of a solution with an extract/MD of $1 / 20(\mathrm{w} / \mathrm{w})$ and a solids content of $21 \%(\mathrm{w} / \mathrm{w})$ and the following atomization conditions: inlet temperature $170{ }^{\circ} \mathrm{C}$, outlet temperature $95{ }^{\circ} \mathrm{C}$, aspiration at $90 \%$ and pump at $20 \%(6$ $\mathrm{mL} / \mathrm{min})$. To prepare the atomizing solution, the extracts $(1 \mathrm{~g})$ were dissolved firstly in 
ethanol $(10 \mathrm{~mL})$ followed by water addition $(90 \mathrm{~mL})$ to achieve a homogenous solution. Thereafter, $20 \mathrm{~g}$ of MD were added under stirring until total dissolution. The equipment was a Mini Spray Dryer B-290 from Büchi (Flawil, Switzerland) used in combination with the Inert Loop B-295 to provide a closed loop circulation under nitrogen atmosphere. The nozzle size was $0.7 \mathrm{~mm}$ and the atomized volume $100 \mathrm{~mL}$.

Microcapsules incorporating the individualized extracts and the chosen synergistic combination of both (Sl:Ca, 1:1) have been prepared. Pure MD microcapsules were also produced to be used as control.

\subsubsection{Microcapsules characterization}

The microencapsulation process was characterized in terms of yield and efficiency. Additionally, the obtained powders were analysed by SEM (to inspect morphology and particle size) and for their antioxidant activity.

The encapsulation yield was determined gravimetrically as the ratio between the weight of microspheres obtained at the end of the process and the weight of the atomized materials (encapsulation material plus extract). It gives an estimative of the material losses during the process.

Encapsulation efficiency (EE) was determined by HPLC-DAD (Heleno et al., 2012; Martins et al., 2014) as the ratio between the experimentally determined encapsulated extract, in terms of cinnamic acid (the major compound identified in the extracts), and the theoretical one. Quantification was based in a calibration curve obtained at $280 \mathrm{~nm}$ by injecting known concentrations $(0.3-50 \mu \mathrm{g} / \mathrm{mL})$ of cinnamic acid $\left(y=972179 x+174853 ; R^{2}=0.999\right)$. The results were expressed as $\mu$ g per mg of extract. 
The antioxidant activity, used to inspect the maintenance of synergistic effects was evaluated by DPPH radical scavenging activity and reducing power assays, according to the methodologies described above. The synergistic effect of the encapsulated extracts was evaluated by testing the microcapsules incorporating the chosen synergistic mixture and the corresponding combination prepared from the two individually microencapsulated extracts.

\subsection{Incorporation of mushroom extracts into cottage cheese and evaluation of antioxidant activity, nutritional composition and colour of the final products}

\subsubsection{Preparation of the cottage cheese samples}

All the cottage cheese samples were prepared by Queijos Casa Matias Lda (Seia, Portugal). Three groups of samples, each one comprising two ewe cottage cheeses (100 g each), were prepared: (i) control sample (cottage cheeses without added mushroom extracts); (ii) cottage cheeses added with microencapsulated extracts ( $3 \mathrm{~g} /$ cheese); and (iii) cottage cheeses added with free extracts $(80 \mathrm{mg} / \mathrm{cheese})$. All the prepared samples contain an equivalent amount of extract $(\mathrm{Sl}: \mathrm{Ca}, 1: 1)$, either in its free or encapsulated form.

\subsubsection{Evaluation of cottage cheese antioxidant, nutritional and colour properties}

The samples (control sample, cottage cheeses added with microencapsulated extracts and cottage cheeses added with free extracts) were evaluated in what concerns antioxidant activity, nutritional composition and colour, immediately after preparation (t0) and after seven days of storage at $4{ }^{\circ} \mathrm{C}(\mathrm{t} 7)$. 
The antioxidant activity was evaluated using DPPH radical scavenging activity and reducing power, following the extraction process and methodologies described above. The nutritional composition (moisture, protein, fat, carbohydrates and ash) was evaluated using the AOAC procedures (AOAC, 2005): the protein content (Nx6.38) was determined using the Kjeldahl method; the fat was determined by Soxhlet extraction with petroleum ether; the ash content was determined by incineration at $600 \pm 15^{\circ} \mathrm{C}$; and total carbohydrates were calculated by difference. Total energy was calculated as Energy $(\mathrm{kcal})=4 \times($ protein weight $(\mathrm{g})+$ carbohydrate weight $(\mathrm{g}))+9 \times($ lipid weight $(\mathrm{g}))$.

Fatty acids were determined by analysing the petroleum ether extract previously obtained, by gas-chromatography coupled with a flame ionization detector (GC-FID), according to the procedure described by the authors (Reis et al., 2011). The identification was made by comparison of the relative retention times of fatty acid methyl esters with standards. The results were expressed as relative percentages.

Sample colour was determined in a colorimeter (model CR-400, Konica Minolta Sensing, Inc., Japan), using the illuminant $\mathrm{C}$ and a diaphragm aperture of $8 \mathrm{~mm}$. The CIE $L^{*} a^{*} b^{*}$ colour space values were registered using the data software "Spectra Magic Nx" (version CM-S100W 2.03.0006) (Caleja et al., 2015). Three readings on the sample top and bottom parts, were used.

\subsection{Statistical analysis}

For each group, two samples were used and antioxidant evaluation assays, nutritional determinations and colour analysis were carried out in triplicate. The results were expressed as mean values \pm standard deviation $(\mathrm{SD})$ and further analysed using one-way 
analysis of variance (ANOVA) followed by Tukey's HSD Test $(\alpha=0.05)$. This analysis was carryout out using SPSS v. 22.0 program (IBM Corp., Armonk, NY, USA).

\section{Results and discussion}

\subsection{Synergistic effects between mushroom extracts}

The results of the antioxidant activity (measured by DPPH radical scavenging activity, reducing power and inhibition of $\beta$-carotene bleaching assays) of the free extracts, $S$. luteus $(\mathrm{Sl})$ and $C$. atramentaria $(\mathrm{Ca})$, and of the prepared mixtures (Sl:Ca 1:2, 1:1 and 2:1, w/w) are shown in Table 1. Comparing the two individualized mushrooms extracts, the lower $\mathrm{EC}_{50}$ values were obtained for $\mathrm{Sl}$ extract, indicating that this mushroom has higher antioxidant activity than $\mathrm{Ca}$. This tendency was also corroborated in previous studies carried out by the authors using different extracting solvents, namely pure methanol (Heleno et al., 2012; Reis et al., 2011). The combination Sl:Ca (1:2) presented the highest $\mathrm{EC}_{50}$ values and, thus, it was discharged for microencapsulation studies. In what concerns to the combinations Sl:Ca (1:1) and Sl:Ca (2:1), both presented propensity for synergistic effects based on DPPH radical scavenging activity and $\beta$ carotene bleaching inhibition assays, even DPPH pointed out for a higher synergistic effect for the $\mathrm{Sl}: \mathrm{Ca}(2: 1)$ (a lower $\mathrm{EC}_{50}$ value was achieved for this combination). In the case of the reducing power assay, the achieved values were quite similar. Analysing the obtained results and taking into account practical aspects of sample preparation, the combination Sl:Ca (1:1) was chosen to proceed with microencapsulation and, thereafter, with food incorporation studies.

\subsection{Microencapsulation of mushroom extracts}




\subsubsection{Encapsulation yield, encapsulation efficiency and SEM analysis}

The lyophilized extracts of $\mathrm{Sl}$ and $\mathrm{Ca}$ alone, as well as their mixture in similar proportions (Sl:Ca, 1:1), were encapsulated by spray-drying with maltodextrin (MD) as the encapsulating material. The main purpose of the microencapsulation was the stabilization of the extracts in order to avoid their oxidation and loss of bioactivity, as also to remove their strong odour. The encapsulation yield (EY) of the spray-drying process was around $50 \%$, in accordance with other published works using MD as the encapsulating material (Wu et al., 2014). Thus the lower value was achieved for the Sl:Ca (1:1) mixture (47.1\%), the highest value was Sl extract $(55.2 \%)$ and the intermediate value of EY corresponds to the Ca extract (51.8\%). The encapsulation efficiency (EE), determined in terms of cinnamic acid (a compound present in the extracts of both mushroom species) was comprised between 43.5-62.6\%. The lower value was achieved with $\mathrm{Ca}$ extract $(43.5 \%)$ and the highest value with $\mathrm{S} 1$ extract (62.6\%). For the $\mathrm{Sl}: \mathrm{Ca}(1: 1)$ mixture an intermediate value was attained (59.8\%). As an illustrative example, Figure 1 shows the chromatograms obtained with pure MD (Figure 1A), S1 extract in its free form (Figure 1B) and Sl extract in its encapsulated form (Figure 1C). As can be observed, cinnamic acid is present in the chromatograms assigned to free and encapsulated S1 extracts but not in the one of pure MD. This evidence corroborates an effective encapsulation of the Sl extract. The same tendency was observed with $\mathrm{Ca}$ extract and $\mathrm{Sl}: \mathrm{Ca}(1: 1)$ mixture (data not shown).

SEM micrographs are shown in Figure $\mathbf{2}$ and evidence a heterogeneous particle size distribution $(2-50 \mu \mathrm{m})$. In a general way particles presented a round shape with both, smooth and rough, surfaces. The appearance of teeth or invaginations on the particles surface, which gives rise to a rough surface, can be attributed to a rapid evaporation of 
water during the drying process (Rosenberg, Kopelman, Talmon, 1985; Wu et al., 2014). Differences were also observed as a function of the encapsulated extracts, particles with rough surface are predominant in the assay performed with the S1 extract (Figure 2A), being almost absent in the one prepared with the mixture Sl:Ca (1:1) (Figure 2C). Also, a larger particle size was registered for this last case.

\subsubsection{In vitro antioxidant properties}

The produced microparticles containing S1, Ca and Sl:Ca (1:1) extracts were evaluated for their antioxidant activity using two different assays (DPPH radical scavenging activity and reducing power). Additionally, a mixture prepared with the individually encapsulated extracts, trying to mimicking the used synergistic mixture ( $\mathrm{Sl}: \mathrm{Ca}, 1: 1)$, was also prepared and tested. The objective was to check the possible advantages of using this strategy over the previous one (both extracts encapsulated in the same microparticle).

The obtained $\mathrm{EC}_{50}$ values for the individually microencapsulated extracts (Mic $\mathrm{S} 1$ ), $\mathrm{Ca}$ (Mic $\mathrm{Ca}$ ) and for the two synergistic mixtures (Mic Sl:Ca, 1:1 and Mic Sl+Mic Ca, 1:1) are shown in Table 2. In what concerns the individualized encapsulated extracts, S1 revealed the higher antioxidant activity, confirming the tendency already observed with the free extract forms. No significant advantage was noticed as a result of the used methodology for mixtures preparation. The obtained $\mathrm{EC}_{50}$ values were quite similar for both preparations, giving the $\mathrm{Sl}: \mathrm{Ca}(1: 1)$ slight better results. In fact, for this mixture the assumption of synergistic effects was achieved with both DPPH radical scavenging activity and reducing power assays. These microspheres, corresponding to a more 
attractive preparation procedure based in a unique step, were then selected for incorporation into cottage cheese.

\subsection{Cottage cheese enriched with mushroom extracts}

\subsubsection{In vitro antioxidant properties}

Table 3 shows the antioxidant activity results of the prepared cottage cheese samples (control cottage cheese without extracts; cottage cheese enriched with $\mathrm{Sl}: \mathrm{Ca}$ (1:1) extract in its free form; and cottage cheese enriched with $\mathrm{Sl}: \mathrm{Ca}(1: 1)$ extract in its microencapsulated form) obtained according with DPPH radical scavenging activity and reducing power assays. It was observed that the incorporation of free extracts resulted in products with higher initial antioxidant activity (t0) but declining after seven days ( $\mathrm{t} 7$ ), which can be associated with their degradation. However, the cottage cheese enriched with the microencapsulated extracts, that have revealed a lower activity at initial time, showed an increase at $\mathrm{t} 7$. This improvement can be explained by an effective protection provided by the used microencapsulation process (spray-drying with MD) together with a sustained release.

The antioxidant increment observed for the control sample, according to the reducing power assay, is compatible with the formation of antioxidant (in this case, reducing) compounds as a result of lipid peroxidation process occurring during cottage cheese storage. Nevertheless, both antioxidant evaluation assays, show a clear cut of tendency pointed out for higher antioxidant preservation over time if microencapsulated extracts are used.

\subsubsection{Colour and nutritional evaluation}


Nutritional evaluation in cottage cheese samples comprised the assessment of protein, fat (including fatty acids profile), carbohydrate and ash contents, as well as, total energy. Table 4 shows the obtained results that pointed out, comparatively with the control sample, for nutritional properties maintenance after the incorporation of mushroom extracts (both in its free and microencapsulated forms). Cottage cheese samples, as expected, showed lipids as the major macronutrients with special contribution from saturated fatty acids. Moreover, the same fatty acids profile was observed in all the samples, with palmitic acid (C16:0) presented at higher content. Oleic (C18:1) and linoleic (C18:2) acids were the major MUFA and PUFA, respectively. Moisture, ash, carbohydrates and energy values are within the range of the reference values for this type of cottage cheese. In same table, colours evaluation of samples indicated no changes due to the extracts incorporation (free and microencapsulated forms) in cottage cheese. In general, the introduction of free and encapsulated extracts did not affect the nutritional value of the cottage cheese when comparing with the control sample.

\section{Conclusions}

In this work, the antioxidant activity of $\mathrm{S}$ and $\mathrm{Ca}$ extracts was evaluated being observed that their combination results in synergistic effects. The spray-drying of the extracts using an extract/maltodextrin ratio of $1 / 20$ and an inlet temperature of $170{ }^{\circ} \mathrm{C}$ resulted in good encapsulation yield (around 50\%) and efficiency (43.5-62.6\%.).

The microencapsulated extracts with maltodextrin did not lose antioxidant activity, being the combination $\mathrm{Sl}: \mathrm{Ca}(1: 1)$ the best as it revealed synergistic effects. The microspheres with $\mathrm{Sl}: \mathrm{Ca}(1: 1)$ and with free extract (in the same proportion) were 
incorporated into cottage cheese. The results showed that, in comparison with the free form, the encapsulated extracts became more effective since the antioxidant activity was preserved along time. The evaluation of nutritional value revealed that the introduction of free and encapsulated extracts did not affect the contents of proteins, fat (and fatty acids), carbohydrates, and ash, when comparing with the control cottage cheese. Also, no colour changes were detected.

\section{Competing interests}

The authors declare no competing financial interest.

\section{Acknowledgement}

Financial support was provided by FCT/MEC and FEDER under Programme PT2020 (LSRE: Project UID/EQU/50020/2013and CIMO: PEst-OE/AGR/UI0690/2014) and QREN, ON2 and FEDER (Project NORTE-07-0162-FEDER-000050 and NORTE-070124-FEDER-000014). G. Ruphuy thanks Universidad de Costa Rica (UCR) and Ministerio de Ciencia, Tecnología y Telecomunicaciones de Costa Rica (MICITT) for her scholarship and L. Barros FCT for her contract (Compromisso para a Ciência 2008). A special thanks to Cargill for having provided us with the maltodextrin sample used in this work (reference C*Dry MD 01915).

\section{References}

Alves, M. J., Ferreira, I.C.F.R., Dias, J., Teixeira, V., Martins, A., \& Pintado, M. (2012). A review on antimicrobial activity of mushroom (Basidiomycetes) extracts and isolated compounds. Planta Med., 78, 1707-10718. 
AOAC. (2005). Official methods of analysis of AOAC international. In W. Horwitz, \& G. Latimer (Eds.) (18 ${ }^{\text {th }}$ ed.) Gaithersburg, MD: AOAC International

Caleja, C., Barros, L., Antonio, A.L., Ciric, A., Soković, M., Oliveira, M.B.P.P., Santos-Buelga, C. \& Ferreira, I.C.F.R., (2015). Foeniculum vulgare Mill. As natural conservation enhacer and health promoter by incorporation in cottage cheese. Journal of Functional Foods, 12,428-438

Çam, M., Içyer, N.C. \& Erdoğna, F. (2014). Pomegranate peel phenolics: Microencapsulation, storage stability and potential ingredient for functional food development. LWT-Food Science and Technology, 55, 117-123.

Carocho, M., \& Ferreira, I. C.F.R. (2013). A review on antioxidants, prooxidants and related controversy: natural and synthetic compounds, screening and analysis methodologies and future perspectives. Food and Chemical Toxicology, 51, 15-25.

Dias, M.I., Ferreira, I.C.F.R., \& Barreiro, M.F., (2015) Microencapsulation of bioactives for food applications. Food \& Function, DOI:10.1039/c4fo01175a

Ersus, S. \& Yurdagel, U., (2007).Microencapsulation of anthocyanin pigments of black carrot (Daucuscorota L.) by spray drier. Journal of Food Engineering, 80, 805-812 
Fang, Z. \& Bhandari, B. (2010). Encapsulation of polyphenols - a review. Food Science \& Technology, 21, 510-523

Ferreira, I.C.F.R, Barros, L., \& Abreu, R.M. (2009). Antioxidants in wild mushrooms. Current Medicinal Chemistry, 16, 1543-1560.

Gharsallaoui, A., Roudaut, G., Chambin, O., Voilley, A. \& Saurel, R. (2007). Applications of spray-drying in microencapsulation of food ingredients: An overview. Food Research International, 40, 1107-1121

Heleno, S. A., Barros, L., Martins, A., Queiroz, M. R., Santos-Buelga, C., \& Ferreira, I.C.F.R. (2012). Phenolic, polysaccharidic, and lipidic fraction of mushrooms from Northeastern Portugal: chemical compounds with antioxidant properties. Journal of Agricultural and Food Chemistry, 60, 4634-4640.

Heleno, S., Ferreira, I.C.F.R., Calhelha, R., Esteves, A.P., Martins, A., \& Queiroz, M.R. (2014). Cytotoxicity of coprinopsis atramentaria extract, organic acids and their synthesized methylated and glucuronate derivatives. Food Research International, 55, $170-175$

Kalač, P., (2009). Chemical composition and nutritional value of European species of wild growing mushrooms: A review. Food Chemistry, 113, 9-16 
Kha, T.C., Nguyen, M.H. \& Roach, P.D., (2010) Effects of spray drying conditions on the physicochemical and antioxidant properties of the Gac (Momordica cochinchinensis) fruit aril powder. Journal of Food Engineering, 98, 385-392

Ma, L., Chen, H., Dong, P., \& Lu, X. (2013). Anti-inflammatory and anticancer activities of extracts and compounds from the mushroom Inonotus obliquus. Food Chemistry, 139, 503-508.

Martins, A., Barros, L., Carvalho, A., Santos-Buelga, C., Fernandes, I., Barreiro, F., \& Ferreira, I. C. (2014). Phenolic extracts of Rubus ulmifolius schott flowers: characterization, microencapsulation and incorporation into yogurts as nutraceutical sources. Food \& Function, 5, 1091-1100

Palacios, I., Lozano, M., Moro, C., D'Arrigo, M., Rostagno, M. A., Martínez, J. A., Villares, A. (2011). Antioxidant properties of phenolic compounds occurring in edible mushrooms. Food Chemistry, 128, 674-678.

Ramalingum, N. \& Mahomoodally, M.F. (2014). The therapeutic potential of medicinal foods. Advances in Pharmacological Sciences, 2014, 1-18

Reis, F.S., Heleno, S.A., Barros, L., Sousa, M.J., Martins, A., Santos-Buelga, C. \& Ferreira, I.C.F.R., (2011). Toward the antioxidante and chemical characterization of mycorrhizal mushrooms from Northeast Portugal. Journal of Food Science, 76, C824$\mathrm{C} 830$ 
Reis, F. S., Barros, L., Martins, A., \& Ferreira, I.C.F.R. (2012). Chemical composition and nutritional value of the most widely appreciated cultivated mushrooms: an interspecies comparative study. Food and Chemical Toxicology, 50, 191-197.

Rosenberg, M., Kopelman, I., \& Talmon, Y. (1985). A scanning electron microscopy study of microencapsulation. Journal of Food Science, 50, 139-144.

Saéns, C., Tapia, S., Chávez, J. \& Robert, P. (2009). Microencapsulation by spray drying of bioactive compounds from cactus pear (Opuntia ficus-indica). Food Chemistry, 114, 616-622

Silva, P.I., Stringheta, P.C., Teófilo, R.F. \& Oliveira, I.R.N. (2013). Parameter optimization for spray-drying microencapsulation of jaboticaba (Myrciaria jaboticaba) peel extracts using simultaneous analysis of responses. Journal of Food Engineering, $117,538-544$

Wu, Y., Zou, L., Mao, J. \& Liu, S., (2014) Stability and encapsulation efficiency of sulforaphane microencapsulated by spray drying. Carbohydrate Polymers, 102, 497-503 
Table 1. Antioxidant activity, expressed as $\mathrm{EC}_{50}$ values $(\mathrm{mg} / \mathrm{mL})$, of individual and combined extracts prepared from $S$. luteus $(\mathrm{Sl})$ and $C$. atramentaria $(\mathrm{Ca})$. Results are presented as mean values $\pm \mathrm{SD}$.

\begin{tabular}{|c|c|c|c|c|c|c|c|c|c|c|c|}
\hline \multirow{2}{*}{ Assay } & \multirow{2}{*}{ S1 } & \multirow{2}{*}{$\mathrm{Ca}$} & \multicolumn{3}{|c|}{$\mathrm{Sl}: \mathrm{Ca}(1: 1)$} & \multicolumn{3}{|c|}{$\mathrm{Sl}: \mathrm{Ca}(1: 2)$} & \multicolumn{3}{|c|}{$\mathrm{Sl}: \mathrm{Ca}(2: 1)$} \\
\hline & & & Theoretical* & Experimental & Effect & Theoretical** & Experimental & Effect & Theoretical*** & Experimental & Effect \\
\hline $\begin{array}{l}\text { DPPH radical } \\
\text { scavenging } \\
\text { activity }\end{array}$ & $2.86 \pm 0.02$ & $4.62 \pm 0.14$ & 3.74 & $3.49 \pm 0.13$ & $\mathrm{SE}$ & 4.04 & $4.07 \pm 0.06$ & $\mathrm{AE}$ & 3.44 & $2.72 \pm 0.02$ & SE \\
\hline $\begin{array}{l}\text { Reducing } \\
\text { power }\end{array}$ & $0.97 \pm 0.02$ & $1.11 \pm 0.02$ & 1.04 & $1.05 \pm 0.02$ & $\mathrm{AE}$ & 1.06 & $1.20 \pm 0.04$ & NS & 1.02 & $0.94 \pm 0.01$ & $\mathrm{SE}$ \\
\hline $\begin{array}{l}\text { Inhibition of } \\
\beta \text {-carotene } \\
\text { bleaching }\end{array}$ & $1.64 \pm 0.20$ & $5.28 \pm 0.36$ & 3.46 & $1.46 \pm 0.04$ & SE & 4.08 & $1.51 \pm 0.07$ & $\mathrm{SE}$ & 2.84 & $1.47 \pm 0.04$ & $\mathrm{SE}$ \\
\hline
\end{tabular}


Table 2. Antioxidant activity, expressed as $\mathrm{EC}_{50}$ values $(\mathrm{mg} / \mathrm{mL})$, of microencapsulated (Mic) individual and combined extracts prepared from $S$. luteus (Sl) and C. atramentaria (Ca). Results are presented as mean values \pm SD.

\begin{tabular}{|c|c|c|c|c|c|c|c|}
\hline \multirow{2}{*}{ Assay } & \multirow{2}{*}{ Mic Sl } & \multirow{2}{*}{$\mathrm{Mic} \mathrm{Ca}$} & \multirow{2}{*}{ Theoretical } & \multicolumn{2}{|l|}{ Mic Sl:Ca (1:1) } & \multicolumn{2}{|c|}{ Mic Sl+Mic Ca (1:1) } \\
\hline & & & & Experimental & & Experimental & Effect \\
\hline $\begin{array}{l}\text { DPPH radical } \\
\text { scavenging activity }\end{array}$ & $2.13 \pm 0.06$ & $2.36 \pm 0.16$ & 2.25 & $1.96 \pm 0.06$ & SE & $2.04 \pm 0.04$ & SE \\
\hline Reducing power & $0.85 \pm 0.01$ & $0.78 \pm 0.01$ & 0.82 & $0.87 \pm 0.01$ & NS & $0.83 \pm 0.02$ & $\mathrm{AE}$ \\
\hline
\end{tabular}

Theoretical value was calculated as weighted mean experimental $\mathrm{EC}_{50}$ values available in individual mushrooms: $\mathrm{EC}_{50}=\mathrm{EC}_{50} \mathrm{Sl} \times 0.50+\mathrm{EC}_{50} \mathrm{Ca} \times 0.50$.

AE- additive effect: theoretical and experimental values reveal differences lower than $5 \%$; SE- synergistic effect: experimental values are more than $5 \%$ lower for EC $\mathrm{C}_{50}$ when compared with theoretical values; NS- negative synergistic (antagonistic) effect: experimental values are more than $5 \%$ higher for $\mathrm{EC}_{50}$ when compared with theoretical values. Mic S1 + Mic Ca (1:1) - mixture prepared with the individually encapsulated extracts for mimicking microspheres with combination Sl:Ca (Mic Sl:Ca). 
Table 3. Antioxidant activity, expressed as $\mathrm{EC}_{50}$ values $(\mathrm{mg} / \mathrm{mL})$, of cottage cheese control and samples enriched with free and microencapsulated extracts prepared from $S$. luteus $(\mathrm{Sl})$ and $C$. atramentaria $(\mathrm{Ca})$ combined in similar proportions (S1:Ca, 1:1). Results are presented as mean values \pm SD

\begin{tabular}{|c|c|c|c|c|c|c|}
\hline \multirow[b]{2}{*}{ Storage days } & \multicolumn{2}{|c|}{ Control cottage cheese } & \multicolumn{2}{|c|}{ Cottage cheese with free extract } & \multicolumn{2}{|c|}{ Cottage cheese with microencapsulated extract } \\
\hline & 0 days & 7 days & 0 days & 7 days & 0 days & 7 days \\
\hline DPPH radical scavenging activity & $>200$ & $>200$ & $83.61 \pm 2.57^{\mathrm{c}}$ & $161.86 \pm 7.28^{\mathrm{a}}$ & $133.44 \pm 4.09^{b}$ & $96.96 \pm 9.33^{\mathrm{c}}$ \\
\hline Reducing power & $>200$ & $56.58 \pm 0.18$ & $14.49 \pm 0.19^{\mathrm{c}}$ & $19.96 \pm 0.70^{\mathrm{b}}$ & $20.46 \pm 0.49^{\mathrm{a}}$ & $13.67 \pm 0.18^{\mathrm{d}}$ \\
\hline
\end{tabular}

In each line, different letters mean statistical significant differences $(\mathrm{p}<0.05)$ between samples. 
Table 4. Nutritional value and colour parameters of the cottage cheese control and samples enriched with free and microencapsulated extracts prepared from $S$. luteus $(\mathrm{Sl})$ and $C$. atramentaria $(\mathrm{Ca})$ combined in similar proportions $(\mathrm{Sl}: \mathrm{Ca}, 1: 1)$, along storage time. Results are presented as mean values \pm SD.

\begin{tabular}{|c|c|c|c|c|c|c|}
\hline \multirow[b]{2}{*}{ Storage days } & \multicolumn{2}{|c|}{ Control cottage cheese } & \multicolumn{2}{|c|}{ Cottage cheese with free extract } & \multicolumn{2}{|c|}{ Cottage cheese with microencapsulated extract } \\
\hline & 0 days & 7 days & 0 days & 7 days & 0 days & 7 days \\
\hline \multicolumn{7}{|l|}{ Nutritional value } \\
\hline $\operatorname{Ash}(\mathrm{g} / 100 \mathrm{~g} \mathrm{fw})$ & $1.48 \pm 0.02^{\mathrm{cd}}$ & $1.69 \pm 0.03^{\mathrm{ab}}$ & $1.35 \pm 0.14^{\mathrm{d}}$ & $1.80 \pm 0.09^{\mathrm{a}}$ & $1.62 \pm 0.10^{\mathrm{bc}}$ & $1.56 \pm 0.05^{\mathrm{bc}}$ \\
\hline Fat $(\mathrm{g} / 100 \mathrm{~g} \mathrm{fw})$ & $16.56 \pm 0.04^{\mathrm{a}}$ & $16.21 \pm 0.00^{\mathrm{bc}}$ & $15.77 \pm 0.08^{\mathrm{de}}$ & $17.67 \pm 0.39^{\mathrm{a}}$ & $15.51 \pm 0.18^{\mathrm{e}}$ & $16.04 \pm 0.04^{\mathrm{cd}}$ \\
\hline Protein $(\mathrm{g} / 100 \mathrm{~g} \mathrm{fw})$ & $12.48 \pm 0.26^{\mathrm{ab}}$ & $12.31 \pm 0.19^{\mathrm{ab}}$ & $12.60 \pm 0.03^{\mathrm{a}}$ & $12.43 \pm 0.03^{\mathrm{ab}}$ & $12.10 \pm 0.00^{\mathrm{b}}$ & $12.45 \pm 0.13^{\mathrm{ab}}$ \\
\hline $\begin{array}{l}\text { Carbohydrates }(\mathrm{g} / 100 \mathrm{~g} \\
\text { fw) }\end{array}$ & $1.15 \pm 0.29^{c}$ & $2.02 \pm 0.20^{\mathrm{a}}$ & $1.03 \pm 0.03^{\mathrm{c}}$ & $2.38 \pm 0.33^{\mathrm{a}}$ & $1.29 \pm 0.06^{\mathrm{bc}}$ & $1.84 \pm 0.13^{\mathrm{ab}}$ \\
\hline Energy (Kcal/100 g fw) & $203.56 \pm 0.09^{\mathrm{bc}}$ & $203.23 \pm 0.07^{\mathrm{b}}$ & $196.44 \pm 0.70^{\mathrm{d}}$ & $218.27 \pm 1.11^{\mathrm{a}}$ & $193.17 \pm 0.93^{\mathrm{e}}$ & $201.53 \pm 0.27^{\mathrm{c}}$ \\
\hline \multicolumn{7}{|l|}{ Fatty acids } \\
\hline $\mathrm{C} 4: 0$ & $6.56 \pm 0.83$ & $8.55 \pm 0.48$ & $9.51 \pm 0.50$ & $7.98 \pm 0.81$ & $8.07 \pm 0.85$ & $8.34 \pm 0.21$ \\
\hline C6:0 & $4.67 \pm 0.42$ & $5.44 \pm 0.52$ & $6.11 \pm 0.23$ & $5.24 \pm 0.49$ & $4.84 \pm 0.02$ & $5.06 \pm 0.37$ \\
\hline $\mathrm{C} 8: 0$ & $3.08 \pm 0.26$ & $3.59 \pm 0.47$ & $3.83 \pm 0.15$ & $3.50 \pm 0.22$ & $3.11 \pm 0.09$ & $3.27 \pm 0.31$ \\
\hline C10:0 & $6.64 \pm 0.35$ & $7.77 \pm 0.96$ & $7.81 \pm 0.26$ & $7.73 \pm 0.32$ & $6.78 \pm 0.27$ & $7.25 \pm 0.53$ \\
\hline C12:0 & $3.26 \pm 0.07$ & $3.67 \pm 0.25$ & $3.54 \pm 0.07$ & $3.71 \pm 0.09$ & $3.38 \pm 0.13$ & $3.48 \pm 0.09$ \\
\hline $\mathrm{C} 14: 0$ & $7.83 \pm 0.04$ & $8.45 \pm 0.06$ & $8.12 \pm 0.07$ & $8.51 \pm 0.06$ & $8.11 \pm 0.29$ & $8.12 \pm 0.09$ \\
\hline C16:0 & $20.90 \pm 0.02$ & $20.44 \pm 0.66$ & $19.98 \pm 0.36$ & $20.74 \pm 0.43$ & $20.55 \pm 0.36$ & $20.74 \pm 0.33$ \\
\hline C18:0 & $13.06 \pm 0.16$ & $11.50 \pm 0.55$ & $11.25 \pm 0.11$ & $11.84 \pm 0.48$ & $12.26 \pm 0.06$ & $12.43 \pm 0.13$ \\
\hline C18:1n9 & $24.99 \pm 0.06$ & $22.45 \pm 0.97$ & $21.82 \pm 0.50$ & $22.64 \pm 0.85$ & $24.21 \pm 0.21$ & $23.02 \pm 0.98$ \\
\hline C18:2n6 & $3.46 \pm 0.04$ & $3.09 \pm 0.18$ & $3.00 \pm 0.03$ & $3.14 \pm 0.10$ & $3.30 \pm 0.05$ & $3.23 \pm 0.04$ \\
\hline SFA (relative \%) & $68.60 \pm 0.15^{\mathrm{a}}$ & $71.81 \pm 1.32^{\mathrm{a}}$ & $72.52 \pm 0.61^{\mathrm{a}}$ & $71.64 \pm 1.02^{\mathrm{a}}$ & $69.62 \pm 0.28^{\mathrm{a}}$ & $71.04 \pm 0.90^{\mathrm{a}}$ \\
\hline MUFA (relative \%) & $26.13 \pm 0.08^{\mathrm{a}}$ & $23.55 \pm 1.01^{\mathrm{a}}$ & $22.95 \pm 0.55^{\mathrm{b}}$ & $23.70 \pm 0.87^{\mathrm{a}}$ & $25.40 \pm 0.23^{\mathrm{a}}$ & $24.12 \pm 1.00^{\mathrm{a}}$ \\
\hline PUFA (relative \%) & $5.27 \pm 0.07^{\mathrm{a}}$ & $4.65 \pm 0.31^{\mathrm{a}}$ & $4.53 \pm 0.07^{\mathrm{c}}$ & $4.65 \pm 0.15^{\mathrm{a}}$ & $4.98 \pm 0.06^{\mathrm{b}}$ & $4.85 \pm 0.11^{\mathrm{a}}$ \\
\hline \multicolumn{7}{|l|}{ Colour parameters } \\
\hline$L^{*}$ & $91.50 \pm 0.85^{\mathrm{a}}$ & $91.05 \pm 2.00^{\mathrm{a}}$ & $91.48 \pm 0.63^{\mathrm{a}}$ & $90.74 \pm 0.87^{\mathrm{a}}$ & $91.10 \pm 0.93^{\mathrm{a}}$ & $90.98 \pm 0.83^{\mathrm{a}}$ \\
\hline$a^{*}$ & $-2.12 \pm 0.14^{b}$ & $-2.07 \pm 0.38^{\mathrm{a}}$ & $-1.90 \pm 0.08^{\mathrm{a}}$ & $-1.74 \pm 0.39^{\mathrm{a}}$ & $-1.93 \pm 0.11^{\mathrm{a}}$ & $-1.74 \pm 0.30^{\mathrm{a}}$ \\
\hline$b^{*}$ & $9.86 \pm 0.31^{b}$ & $11.43 \pm 1.60^{\mathrm{a}}$ & $10.23 \pm 0.80^{\mathrm{b}}$ & $12.39 \pm 1.79^{\mathrm{a}}$ & $11.11 \pm 0.46^{\mathrm{a}}$ & $11.21 \pm 1.58^{\mathrm{a}}$ \\
\hline
\end{tabular}
acid (C16:0); stearic acid (C18:0); oleic acid (C18:1n9); linoleic acid (C18:2n6); SFA- Saturated fatty acids; MUFA- Monounsaturated fatty acids; PUFA- Polyunsaturated fatty 


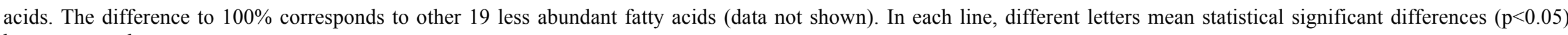
between samples. 

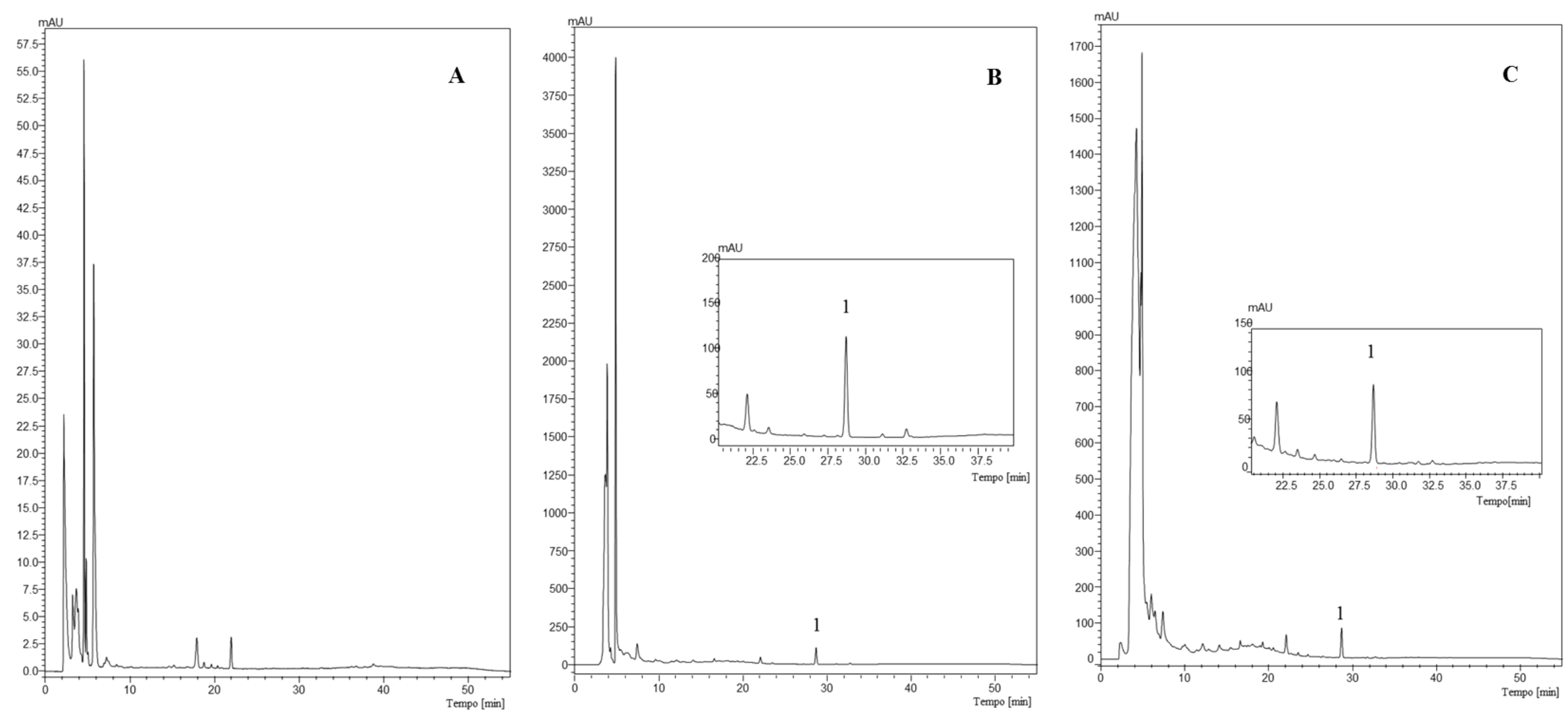

Figure 1. Chromatograms obtained at $280 \mathrm{~nm}$ of maltodextrin (A),free S. luteus (Sl) extract (B) and microspheres with Sl extract (C). 1- Cinnamic acid. 

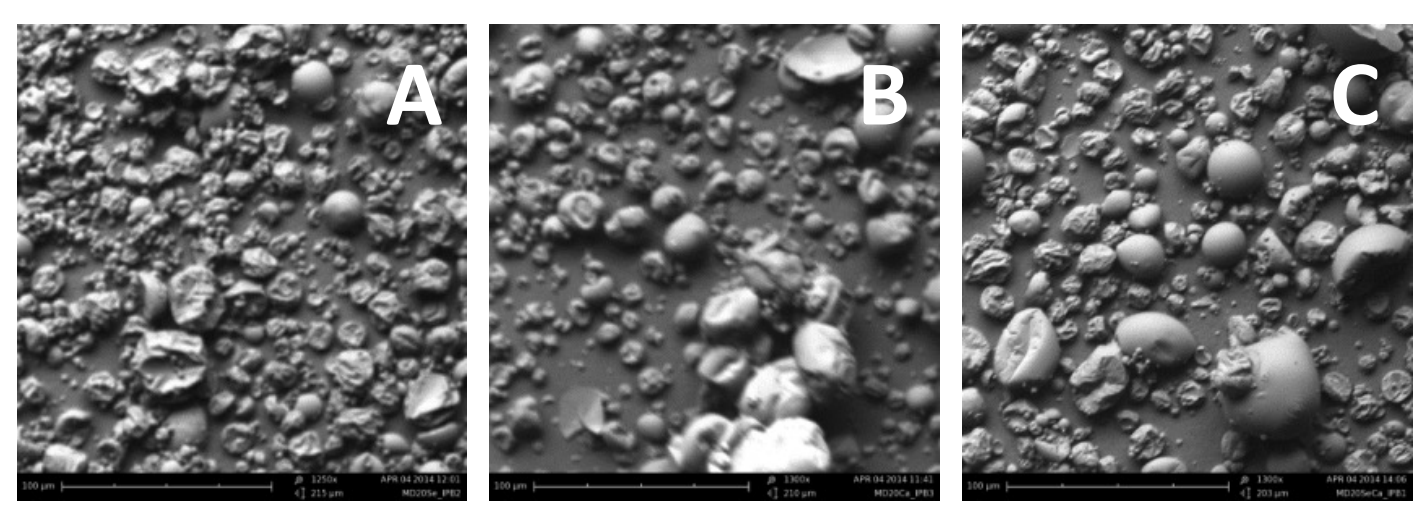

Figure 2. SEM analysis of microparticles containing $S$. luteus extract $(\mathrm{S} 1)(\mathbf{A})$, C. atramentaria extract $(\mathrm{Ca})(B)$ and the mixture $\mathrm{Sl}$ :Ca (1:1) under a magnification of $1300 x$. 